PNP 2021

Personality in norm and in pathology

\title{
STRESS RESISTANCE OF STUDENTS-DEFECTOLOGISTS BEFORE AND DURING THE COVID-19 PANDEMIC
}

\author{
Valeriya Ragozinskaya (a)*, Irina Kozyrskaya (b) \\ *Corresponding author \\ (a) the Department of Special and Clinical Psychology, Chelyabinsk State University, 129 Kashirin brothers street, \\ Chelyabinsk, Russia, ragozinskaya@gmail.com \\ (b) the Department of Special and Clinical Psychology, Chelyabinsk State University, 129 Kashirin brothers street, \\ Chelyabinsk, Russia, irina.kozyrskaya@mail.ru
}

\begin{abstract}
Stress resistance of future special education teachers (defectologists) is a professionally important quality formed in the process of educational and professional activity. The COVID-19 pandemic has created a long list of new stressors for students-defectologists to deal with. Therefore, the requirements for the stress-resistance of a student-defectologist increase significantly with the advent of the COVID-19. The aim of this study is to investigate the features of student-defectologists' stress-resistance before and during the COVID-19 pandemic. The study was carried out in two stages. At the first stage (prepandemic), conducted in November 2019, a group of 110 students-defectologists was tested with the use of standardized questionnaires for assessing stress-resistance. At the second stage (in April 2020) the students completed an online survey that measured the COVID-19-related stressors and coping strategies. According to the research made, before the onset of the COVID-19 the most testees had a moderate level of stress-resistance, but its components were developed unevenly: intellectual, volitional, motivational, operational, and cognitive components are developed moderately. The level of development of the emotional and psychophysiological components was reduced. An online survey during the COVID-19 pandemic has shown a large number of stressors for the most testees. $41 \%$ of respondents report significant stress levels. Many of them show a psychological disequilibrium. Most of the testees use predominantly constructive coping strategies, but the subjects with higher levels of stress more often use avoidance and maladaptive coping strategies. Correlations show that the increased use of avoidance is associated with the increasing levels of stress.
\end{abstract}

2357-1330 @ 2021 Published by European Publisher.

Keywords: COVID-19, stress, stress resistance, stress-resistance components, student-defectologists 


\section{Introduction}

The coronavirus (COVID-19) pandemic and the lockdown caused certain changes in the society that led to the considerable changes in the life of every person. The duration and uncertainty of the current situation, due to the special characteristics of the COVID-19, has evoked great fear in many people, jeopardizing the possibility of meeting basic human needs. An analysis of the occurred changes has shown that the situation associated with the coronavirus pandemic has a high stress potential, and the overall scale of the disaster allows us to consider it as a global traumatic stressor (Brunier \& Harris, 2020; Enikolopov et al., 2020; Holmes et al., 2020). The cumulative stress effect caused by this situation is a factor of increasing anxiety, fear, melancholy and depression (due to the impossibility of a quick resolving the situation), the appearance or intensification of psychopathological symptoms, etc. (Enikolopov et al., 2020).

Students faced difficulties associated with the management of educational and professional activities during the pandemic (Aristovnik et al., 2020; Gritsenko et al., 2020; Gonzalez et al., 2020). The introduction of the self-isolation regime and the temporary transition to e-learning using distance educational technologies actualized the importance of the competencies associated with the involvement of stress resistance mechanisms in response to the adverse factors (Elmer et al., 2020; Kamarianos et al., 2020; Kaparounaki et al., 2020; Khattar et al., 2020). So, the subject of our research is the development and transformation of the stress resistance mechanisms. The students-defectologists have become our testees as for them it is a basic competence and an important integral characteristic of the personality that determines an effective preparation, both for future professional, pedagogical activities, and the ability to respond to any negative impact on a daily basis without any special harmful consequences for physical, mental and social well-being.

\section{Problem Statement}

Numerous foreign studies are fair to say that teaching people with special educational needs is one of the most stressful professions (Baranov, 2002; O'Brien et al., 2019; Rustamova, 2015; Zhang et al., 2020). Psycho-emotional stress in the activities of special education (SPED) teachers (or teachersdefectologists) is associated with emotional and moral overloads caused by working with people with disabilities, and it specifies particular requirements for the level of psychological stability of the students who have chosen this profession (Ivanova \& Makarova, 2015). A number of studies have shown that even beginning SPED teachers and students are subject to professional stress (Fimian \& Blanton, 1986; Klassen \& Chui, 2011). Stress negatively affects a special educator's purpose, job satisfaction, and career decisions (Cancio et al., 2018). Therefore, the ability to cope with the life event stressors and stressful demands of the profession is acknowledged in the literature as an important factor in the professional development of practicing and pre-service SPED teachers and students-defectologists (Dev, 2018; Klassen \& Chui, 2011; Zhang et al., 2020). The success and effectiveness of training for the professional and pedagogical activity of the future defectologist, the level of his professional health are determined by such an integral characteristic of an individual as stress resistance. 
Stress resistance the ability of an individual, a group, an organization, or even an entire population to withstand manifestations of clinical stress, disorders or dysfunctions associated with critical events, terrorism, and even mass disasters (Nucifora et al., 2007). It is a set of personal qualities that allow a person to adapt to the effects of extreme external and internal factors, successfully resolve stressful situations, overcome stress and endure significant intellectual, volitional and emotional stress caused by the peculiarities of his life, especially professional activity, without any special harmful consequences for activities, other people and his health (Kovaleva, 2016).

The scientific literature analysis carried out within the framework of our study has shown that there exist several methodological approaches to the study of stress resistance: the systemic approach and the subject-activity approach (Bokhan, 2008), the deficit model (Cunningham, 2015), the phenomenological approach (Cunningham, 2015; Downing, 2017), the holistic model (Simmons \& Nelson, 2007), the competence-based approach (Waltz, 2016) and so on (for a review, see Ragozinskaya et al., 2020).

The most developed models of stress resistance are based on the principles of the systemic approach and the competence-based one.

The systemic approach understands stress resistance as a systemic, dynamic, and multicomponent psychological system. According to Vizitova (2012), teachers' stress resistance is a complex personal characteristic, determined by a practical support for three main components: emotional (neuropsychic balance, emotional balance); behavioral (activity, a strive for self-development and self-knowledge, assertive behavior, tolerance, communicative and interpersonal skills); cognitive (an auto-psychological competence, the ability to set goals and achieve results, develop skills to overcome stressful situations successfully). According to Katunin (2016), stress resistance can be considered as a dynamic structure of a personality, the main components of which are: emotional, accumulated in the process of overcoming difficult situations and manifested in confidence, in a feeling of inspiration and satisfaction from the task; volitional, which is expressed in self-control, self-possession, conscious self-regulation of actions, bringing them in line with the requirements of the situation; this component performs a control and evaluation function of preserving and restoring the appropriate regulation of the activity; intellectual, reflecting mental performance, a settled mode of thinking. The additional components of stress resistance are: motivational, psychophysiological, operational, communicative, and cognitive (Katunin, 2016).

According to the competence-based approach, competencies are defined as behavioral patterns or personality characteristics that affect performance at work, and stress resistance is understood as one of the priority competencies that has to be developed (Waltz, 2016). Stress resistance of a SPED teacher is understood here both as a condition and as a consequence of his competence development. Competence development is considered a preventive strategy of burnout.

All above-mentioned approaches organically complement each other, defining SPED teachers' stress resistance as a complex psychological phenomenon resulting from the interaction of many factors, such as: optimism and positive attitude, initiative, flexibility, social and emotional competence, communication skills, professional skills, self-efficacy, the ability to assess stressors, understanding the underlying causes of stress and its likely consequences, the ability to change behavior that leads to stress, 
time management, constructive coping strategies, passion for profession and passion for working with children with disabilities (Cunningham, 2015; Downing, 2017; Kebbi, 2018; Waltz, 2016).

Thus, the scientific and theoretical analysis carried out within the framework of our research allows us to state that stress resistance of special education teachers is one of the priority competencies that formed in the process of educational and professional activity. According to the advanced Russian and foreign psychologists, the stress resistance is mainly considered as a systemic, dynamic, and multicomponent psychological system, that allows coping with stressful situations successfully (in professional activities as well). However, the lack of research on stress resistance of studentsdefectologists does not allow us to substantiate ways, strategies and main directions of overcoming stressful states in the process of the professional development of a future special education teacher. The COVID-19 pandemic has created a long list of new stressors for students-defectologists to deal with. But the ways that allow a future defectologist to mobilize for an adequate assessment of the stressful influences and effective overcoming of stress are still insufficiently studied. These circumstances determined the direction and essence of our empirical stress resistance study of students-defectologists in dynamics: before and during the COVID-19 pandemic.

\section{Research Questions}

The study was carried out in two stages. At the first stage (pre-pandemic), conducted in November 2019, the research questions were:

3.1. What are the levels of stress resistance and its components among students - future special education teachers (defectologists)?

At the second stage, conducted in April 2020 (during the COVID-19 pandemic), the research questions were:

3.2. What is the prevalence of stress and its resistance levels among students-defectologists?

3.3. What are the adaptive and maladaptive strategies for overcoming stress among studentsdefectologists?

\section{Purpose of the Study}

The purpose of this study is to investigate the features of student-defectologists' stress-resistance before and during the COVID-19 pandemic.

\section{Research Methods}

The empirical study carried out on the basis of the Chelyabinsk State University in the 2019-2020 academic years had two stages. At the first stage, conducted in November 2019, 110 students of 1-4 courses enrolled in the Bachelor's program of the special (defectological) education took part in the study. 
The age of the examined students varies from 18 to 22 years old. All respondents expressed their voluntary informed consent to participate in the study.

At the first stage, as a theoretical basis for the empirical research, we relied on the multicomponent structure of stress resistance (Katunin, 2016), but taking into account the specifics of the professional training of the future teachers-defectologists. We used the following set of psychodiagnostic methodologies: The perceptual assessment of the stress resistance type, The stress sensitivity test, the multilevel personality questionnaire "Adaptability" (MLO-AM); Forecast-2, The subjective control level (USK), the tapping test, Characteristics of emotionality, The method for diagnosing the type of emotional reaction to the impact of environmental stimuli, Coping inventory for stressful situations (CISS), The psychovegetative questionnaire, Diagnostics method of learning motivation in pedagogical university students.

During the second stage of our empirical study, carried out from April, 28 to May, 11, 2020, there were investigated 56 students, which were a part of the first stage sample of participants. The peculiarity of this stage of the study was determined by the social situation associated with the COVID-19 pandemic, which actualized the involvement of the mechanisms of stress resistance of the future teachersdefectologists in response to the influence of a complex of unfavorable factors of the external and internal environment. We used a questionnaire as a core research method. The survey was conducted in a remote format on the condition of voluntary anonymity using a specially designed questionnaire.

The questionnaire consisted of three blocks:

- the first block was aimed at clarifying the subjective assessment of the respondents' stress burden of the COVID-19 pandemic; the respondents were asked to evaluate on a five-point scale the degree of stressfulness of this situation as a whole and its individual components (threat to personal health, threat to the health of relatives and friends, communicative deficit, inability to study and work freely, motor deficit, uncertainty of the situation, etc.);

- the second block was aimed at determining the severity of the general syndrome of psychological stress and its main sub-syndromes; the respondents were asked to rate themselves on a five-point scale according to the severity of various emotional-behavioral, vegetative, cognitive, and socio-psychological manifestations of stress;

- the third block was aimed at assessing the degree of tension in the respondents' defensive system and at determining the "share" of various coping strategies used by respondents to cope with this situation; the respondents were asked to evaluate on a five-point scale the frequency of using various types of coping with this situation.

Based on the results of the survey, all respondents that agreed to take part were interviewed. For statistical data processing Spearman's rank correlation coefficient was used.

\section{Findings}

\subsection{The results of the first stage}


Some of the results of the primary analysis of the data obtained at the first stage of the research were published earlier (Ragozinskaya et al., 2020). This paper discusses the results of the components and levels of the students-defectologists' stress resistance studying.

The emotional component of the respondents' stress resistance is characterized by a number of features. According to the results based on the questionnaire "Characteristics of emotionality", in general, the examined persons have an increased emotional excitability (the average value is about $4.09 \pm 2.16$ ), the

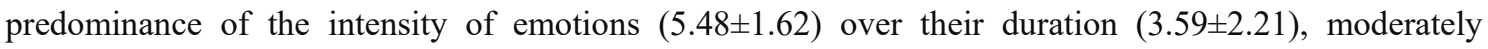
expressed negative influence of emotions on the efficiency of activity and communication (4.13 \pm 1.83$)$. According to the results based on the "CISS", the testees are characterized by the predominance of the

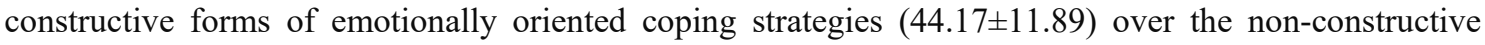
ones (50.59 \pm 8.66$)$. According to the results based on "The method for diagnosing the type of emotional reaction to the impact of environmental stimuli", there prevail the euphoric (19.65 \pm 6.69$)$ and refractory (15.41 \pm 4.70$)$ types of emotional responses to the environmental stimuli. On the one hand, the testees are characterized by the predominance of positive mood background, a tendency to reveal their feelings freely, an expectation of mainly positive stimuli and a willingness to overcome life difficulties. On the other hand, they are characterized by a reluctance to take into account the probability of negative events, by an inability to get rid of negative emotions (bad aftertaste, undercurrent of melancholy) and a feeling of disappointment completely in case of the unrealized expectations.

The volitional component of the respondents' stress resistance is characterized by the following features. According to the results of the "MLO-AM", most of the respondents demonstrate a moderately high level of moral normativity (5.41 \pm 1.28$)$, which ensures the stability of the regulating behavior process, the ability to perceive moral and ethical norms and requirements of the social environment adequately. According to the results of "The perceptual assessment of the stress resistance type", the

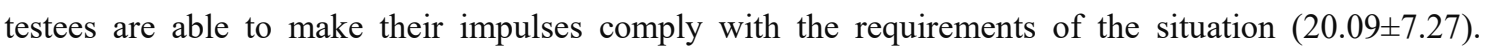
According to the results of the "USK", they are characterized by a moderately expressed willingness to


respondents show a high level of the subjective control in relation to their own achievements (7.39 \pm 2.50$)$ and a low level of the subjective control in relation to the family problems (5.74 \pm 2.33$)$ and work relations (5.74 \pm 2.30 ), which can make the behavior regulation in these areas of relations less stable.

The intellectual component of the respondents' stress resistance has the following features. Most of the respondents demonstrate a sufficient level of mental performance and a moderate ability to carry out a current analysis of the situation and assess its requirements. According to the results of the "CISS", in the situations of moderate stress exposure they tend to use coping strategies mainly aimed at resolving problem situations (59.02 \pm 7.95$)$. However, according to the results based on "The method for diagnosing the type of emotional reaction to the impact of environmental stimuli", the testees have a tendency to overestimate the probability of positive events $(10.12 \pm 3.21)$ and underestimate the probability of negative events (5.36 \pm 3.79$)$. Because of this, the ability of the testees to predict the dynamics of the situation is a little bit reduced. The reduced predictive ability and a tendency to underestimate the probability of a negative development of the situation in some cases can lead to the non-optimal action choice. 
The motivational and cognitive components of the respondents' stress resistance are characterized by the following features. According to the results based on the "Diagnostics method of learning

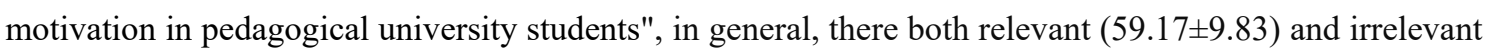
types of professional motivation $(63.39 \pm 11.48)$ are found in the surveyed group. At the same time most of the respondents have an irrelevant professional motivation, an external motivation for entering the university and narrow cognitive motives. The insufficiently high aspiration of these testees to perform the professional tasks largely determines the decrease in their emotional stability. Such a ratio of motives and needs is not always able to ensure the stability of the behavior regulation process in a stressful situation associated with the educational or professional activity of a defectologist.

The psychophysiological component of the respondents' stress resistance has the following characteristics. According to the results of the tapping test, most of the students have a medium-strength type of the nervous system, which limits the ability of the testees to cope with large and long-term loads of psycho-emotional factors of a stressful situation, and, under certain circumstances can negatively affect the functional state of the nervous system, exacerbating adaptation processes. According to the results of "The stress sensitivity test", the majority of respondents are characterized by moderate stress sensitivity due to the peculiarities of their higher nervous activity $(69.39 \pm 30.06)$. At the same time, half of the students show a tendency to complicate things, which, in turn, can lead to stress. According to the results of "The psychovegetative questionnaire", weak and moderate disorders of the vegetative tone of psychogenic nature, associated with the influence of stress factors, prevail in the examined group. According to the results of the "MLO-AM", half of the testees have signs of asthenia as manifestations of maladjustment (5.41 \pm 1.28$)$.

The communicative component of the respondents' stress resistance has the following characteristics. According to the results of the "MLO-AM", most of the respondents show a moderately expressed need for communication and a moderate communicative potential. That is the ability to achieve contact and mutual understanding with others, readiness and ability to interact with the social environment both in everyday educational and professional activities, and in a stressful situation

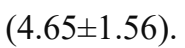

The operational component of the respondents' stress resistance has the following characteristics. Most of the respondents have such a level of proficiency in methods and techniques used which corresponds to their current level of general and professional training, awareness and readiness to perform certain specific tasks of educational and professional activity. Most of the respondents have a constructive style of behavior prevailing in the stressful situations. The use of the strategies that are more focused on the problem solving is based on the use of the available personal and activity resources, regulation mechanisms and the manifestation of the operational component of stress resistance.

Summarizing the results of the first stage of the study, we have come to the conclusion that the stress resistance indicators of the surveyed students are at a satisfactory level, but their individual components are developed unevenly: volitional, intellectual, motivational, operational, and cognitive components are developed moderately. The level of development of the emotional and psychophysiological components is reduced. 


\subsection{The results of the second stage}

The analysis of the second stage results of the study shows that the overwhelming majority of respondents assess the situation associated with the COVID-19 pandemic as stressful to one extend or another: $41 \%$ of respondents have noted a high level of stress in this situation, an average level is noted by $54 \%$ of respondents, only $5 \%$ of the surveyed do not perceive this situation as stressful.

The assessment of the situation in terms of stress factors allows us to state that the most significant aspects related to the COVID-19 pandemic for respondents are: anxiety for the health of relatives and friends (3.93 points on a five-point scale); anxiety caused by a general situation of uncertainty (3.7 points); a psycho-cultural deprivation (3.67 points). The anxiety caused by the uncertainty of the socioeconomic situation in the country (3.39 points), a social deprivation (forced isolation, disunity, inability to communicate with the relatives and friends) (3.37 points), anxiety for one's own health ( 2.93 points); a motor deprivation (2.75 points) is less becoming a source of stress, which corresponds to the average level. It should be underlined that none of the aspects of the situation causing anxiety makes the respondents show a low level; all of them are, to one extend or another, significant for the them and become a source of stress.

The analysis of the indicators of the stress situation general assessment associated with the COVID-19 pandemic shows that a mild degree of manifestation of psychological stress syndrome was shown by $73.2 \%$ of respondents, an average degree of severity is shown by $21.4 \%$ of the respondents, a strong degree of manifestation of psychological stress syndrome is revealed at $5.4 \%$ of the surveyed.

The research results of the severity of the psychological stress syndrome manifestations show that, in general, the manifestations of all the main sub-syndromes of stress have a mild degree of severity. At the same time, the highest indicators are found on the scale of cognitive and socio-psychological stress sub-syndromes. The respondents most often report on such manifestations of the cognitive sub-syndrome of stress as a preoccupation with repetitive ruminations, absent-mindedness, forgetfulness, and decreased ability to concentrate and think constructively. These changes in cognitive functions are mild for the most respondents (66\%), for $23.2 \%$ of respondents they are moderately expressed, for $10.7 \%$, the manifestations of the cognitive sub-syndrome of stress are expressed intensively.

The socio-psychological sub-syndrome of stress manifests itself in the form of a feeling of "incomprehensibility" by others, "abandonment" by everyone, "isolation from the world", a decrease in need for communication, etc. For the majority of the surveyed, stressful changes in communication are mild $(62.5 \%)$, for $17.9 \%$ of the respondents they are moderate, for $19.6 \%$ they are expressed considerably.

The emotional-behavioral sub-syndrome of stress manifests itself in the form of anxiety, agitation, overexcitement states, as well as in the form of a reduced ability to control emotions, mood, actions, etc. These manifestations for most students (69.6\%) are expressed in a mild degree. They are moderately expressed for $12.5 \%$ of the respondents. For $17.9 \%$. the manifestations of the emotional-behavioral subsyndrome of stress are strongly expressed.

The manifestations of the vegetative stress sub-syndrome appear in the form of a general feeling of fatigue, a constant feeling of dry mouth, a lump in the throat, appetite disorders, digestive problems, constant tension of the neck muscles, a feeling of heaviness in the shoulders, back ache, sudden 
temperature changes ("hot and cold by turns") as noted by the respondents. Some students note looking tired and having bags or circles under their eyes.

The majority of the surveyed (71.5\%) have a mild degree of these manifestations, $21.4 \%$ of the respondents have moderately expressed ones, and $7.1 \%$ have strong vegetative stress sub-syndrome manifestations.

The analysis of the coping strategies used by respondents to cope with stress and negative experiences associated with the COVID-19 pandemic shows that constructive coping strategies prevail among respondents: coping focused on solving a problem (3.64 points), emotion-oriented coping (3.04 points). Coping focused on avoidance, that is deflection and social distraction as a way of coping with stress received an average score of 2.48 and 2.11 points, respectively.

At the same time, most often the respondents note that they tend to solve problems as they arise and, until the situation with the pandemic touches them or their relatives, they generally try not to think about it. The non-constructive coping strategy has received the minimum choice (1.66 points), which corresponds to the low level of its implementation by the respondents when choosing the tactics of coping with stress.

\subsection{The correlation analysis results}

Analyzing the relationship between the indicators of the scales of the three blocks of the questionnaire, it can be noted that a larger repertoire of coping strategies in the process of choosing tactics for coping with stress is noted among respondents who assess the situation associated with a pandemic as more stressful and note a higher level of manifestations of the psychological stress syndrome.

When correlating the results of the first and the second stages of our study, the following relationships were revealed. The tendency to feel anxiety about their own health was more expressed in those students who, prior to this situation, had demonstrated an insufficient level of neuropsychic stability $(\mathrm{r}=0.283 ; \mathrm{p} \leq 0.05)$, an attitude exclusively towards positive stimuli of the environment (an euphoric type of emotional reactions; $r=0.320 ; p \leq 0.05)$, a high level of internality $(r=0.326 ; p \leq 0.05)$, a tendency to selfaccusation in case of failure $(r=0.274 ; p \leq 0.05)$ and in case of illness $(r=0.300 ; p \leq 0.05)$, a tendency to use avoidance strategies as the predominant way of coping with difficulties in life $(r=0.286 ; p \leq 0.05)$. They have the most expressed emotional-behavioral $(r=0.291 ; \mathrm{p} \leq 0.05)$ and socio-psychological $(\mathrm{r}=0.292$; $\mathrm{p} \leq 0.05$ ) stress sub-syndromes in the pandemic situation. To cope with stress, they tend to use predominantly constructive emotion-focused coping $(\mathrm{r}=0.516 ; \mathrm{p} \leq 0.01)$, coping focused on social distraction ( $\mathrm{r}=0.491 ; \mathrm{p} \leq 0.01)$ and problem-oriented coping $(\mathrm{r}=0.338 ; \mathrm{p} \leq 0.05)$.

Uncertainty anxiety is more expressed in those students who, before the pandemic, had such psychological characteristics as a mood exclusively for positive environmental stimuli (an euphoric type of emotional reactions; $\mathrm{r}=0.331 ; \mathrm{p} \leq 0.05)$, vivid sympathicotonia $(\mathrm{r}=0.284 ; \mathrm{p} \leq 0.05)$. The pandemic situation is assessed by these students as the most stressful one $(\mathrm{r}=0.545 ; \mathrm{p} \leq 0.01)$, due to the social deprivation $(\mathrm{r}=0.322 ; \mathrm{p} \leq 0.05)$, psycho-cultural deprivation $(\mathrm{r}=0.420 ; \mathrm{p} \leq 0.01)$, the uncertainty of the socio-economic situation $(\mathrm{r}=0.485 ; \mathrm{p} \leq 0.01)$. They have the most expressed socio-psychological subsyndrome of stress $(\mathrm{r}=0.370 ; \mathrm{p} \leq 0.01)$, which manifests itself in the form of stressful changes in communication. To cope with stress during the pandemic, they tend to use all types of coping strategies: 
emotion-focused coping $(\mathrm{r}=0.316 ; \mathrm{p} \leq 0.05)$, distraction-oriented coping $(\mathrm{r}=0.278 ; \mathrm{p} \leq 0.05)$, social distraction-oriented $(\mathrm{r}=0.287 ; \mathrm{p} \leq 0.05)$, and problem-focused coping $(\mathrm{r}=0.278 ; \mathrm{p} \leq 0.05)$. They are characterized by the general tension of the coping system $(r=0.363 ; \mathrm{p} \leq 0.01)$.

The manifestations of the stress syndrome are more expressed in those students who, prior to this situation, had such psychological characteristics as: low adaptive abilities $(\mathrm{r}=-0.275 ; \mathrm{p} \leq 0.05)$, neuropsychic instability $(\mathrm{r}=-0.267 ; \mathrm{p} \leq 0.05)$, an internal locus of control in the sphere of failures $(\mathrm{r}=0.267$; $\mathrm{p} \leq 0.05$ ), attunement to the ambivalent environmental stimuli that "get stuck in the personality "in the form of an unpleasant aftertaste, reflections, hidden sadness, anger (a refractory type of emotional reactions; $r=0.467 ; \mathrm{p} \leq 0.01)$, high stress sensitivity $(\mathrm{r}=0.364 ; \mathrm{p} \leq 0.05)$, vivid sympathicotonia $(\mathrm{r}=0.392$; $\mathrm{p} \leq 0.01)$. The pandemic situation is assessed by them as the most stressful $(\mathrm{r}=0.312 ; \mathrm{p} \leq 0.05)$. Such aspects of this situation as a threat to the health of relatives and friends $(r=0.338 ; p \leq 0.05)$ and the uncertainty of the socio-economic situation $(\mathrm{r}=0.430 ; \mathrm{p} \leq 0.01)$ are also assessed. In the COVID-19 pandemic situation, they have the most expressed emotional-behavioral $(\mathrm{r}=0.928 ; \mathrm{p} \leq 0.01)$, vegetative $(\mathrm{r}=0.935 ; \mathrm{p} \leq 0.01)$ and cognitive ( $r=0.824 ; \mathrm{p} \leq 0.01)$ stress sub-syndromes. To cope with stress in the COVID-19 pandemic, they tend to use predominantly non-constructive emotion-focused coping $(r=0.276 ; p \leq 0.05)$ and avoidance coping ( $\mathrm{r}=0.453 ; \mathrm{p} \leq 0.01)$. They are characterized by a common tension of the coping system $(\mathrm{r}=0.370$; $\mathrm{p} \leq 0.01$ ). Correlations show that the increased use of avoidant coping is associated with the increasing levels of stress ( $r=0.360 ; p \leq 0.05)$. It is known that escape and avoidance, as coping strategies, can have some short-term positive effects, but in the long run they can exacerbate stress.

Those students who, before the pandemic, had such psychological characteristics as neuropsychic stability ( $\mathrm{r}=-0.268 ; \mathrm{p} \leq 0.05)$, high adaptive abilities $(\mathrm{r}=-0.275 ; \mathrm{p} \leq 0.05)$, adequate sensitivity to stress $(\mathrm{r}=-$ $0.350 ; \mathrm{p} \leq 0.05)$, and a tendency to use mostly problem-focused coping $(\mathrm{r}=-0.477 ; \mathrm{p} \leq 0.01)$ and constructive emotion-focused coping $(\mathrm{r}=-0.492 ; \mathrm{p} \leq 0.01)$ in the stressful situations are less subject to stress and recover more quickly. To cope with stress during the pandemic, they tend to use predominantly constructive emotion-focused coping (such as seeking social support, using systematic relaxation procedures - yoga, meditation, deep breathing techniques, music and art therapy; $r=-0.571 ; p \leq 0.01$ ). It is known that constructive emotion-focused coping strategies are well suited for stressors that seem uncontrollable. It is these stressors that are most characteristic of the exponential phase of the COVID-19 pandemic.

\section{Conclusion}

Thus, as a result of the first stage of the study, it was revealed that the level of stress resistance of the surveyed students is generally satisfactory, however, individual components of stress resistance are developed unevenly: volitional, intellectual, motivational, operational and cognitive components correspond to the average level of development, the level of development of emotional and psychophysiological components is reduced.

The analysis of the second stage of the survey suggests that the majority of respondents assessed the overall situation associated with the COVID-19 pandemic as moderately stressful. At the same time, such aspects of this situation as a threat to the health of relatives and friends, the general uncertainty of the situation and the inability to study freely and do what they like, have a high level of stress for them. 
Uncertainty of the socio-economic situation in the country, the inability to communicate freely with relatives and friends, colleagues and classmates, a threat to their own health and a lack of physical activity have a moderate level of stress for respondents.

The majority of respondents have mild manifestations of psychological stress syndrome. The main stress sub-syndromes are also mild in most of the surveyed students. The highest indices were found on the scale of cognitive and socio-psychological stress sub-syndromes, but even they do not go below the normal range for the students surveyed.

Most of the respondents use predominantly constructive strategies for coping with stress. At the same time, a larger repertoire of coping strategies in the process of choosing tactics for coping with stress is noted among respondents who assess the situation associated with a pandemic as more stressful and have a higher level of manifestations of psychological stress syndrome.

A correlation analysis of the first and the second stages results of the survey shows that in the COVID-19 pandemic, those students who have such psychological characteristics as a tendency to use mostly the avoidance strategy of coping with life difficulties, maladaptive disorders (including reactions of the asthenic and psychotic type), a mood exclusively for positive stimuli of the environment (an euphoric type of emotional reactions) and a tendency to self-blame in case of failure, an excitable type of the nervous system and expressed sympathicotonia are more subject to stress. Those students who have such psychological characteristics as neuropsychic stability, high adaptive abilities, adequate stress sensitivity, and a tendency to use mostly the constructive emotion-focused coping and problem-focused coping in the stressful situations are less subject to stress and recover more quickly.

Summing up the results of our empirical research, we note that stress resistance is an important psychological quality and a basic competence important for future teachers-defectologists formed in the process of educational and professional activities. The study of the mechanisms of its development and manifestation allows us to formulate the essence of this phenomenon and substantiate the methods and main directions of overcoming stressful conditions in the process of professional and pedagogical development and determine the main ways to prevent the consequences of psychological stress associated with the COVID-19 pandemic.

\section{Acknowledgments}

We would like to thank Olga Stadnik for her help with data collection at the first stage of the study.

\section{References}

Aristovnik, A., Keržic, D., Ravšelj, D., Tomaževic, N., \& Umek, L. (2020). Impacts of the COVID-19 Pandemic on Life of Higher Education Students: A Global Perspective. Sustainability, 12, 8438. https://doi.org/10.3390/su12208438

Baranov, A. A. (2002). Psychology of teacher's stress resistance: theoretical and applied aspects [Doctoral dissertation, Saint Petersburg University]. https:/www.dissercat.com/content/psikhologiyastressoustoichivosti-pedagoga-teoreticheskie-i-prikladnye-aspekty

Bokhan, T. G. (2008). Cultural-historical approach to stress and stress resistance [Doctoral dissertation, Tomsk State University]. https://www.dissercat.com/content/kulturno-istoricheskii-podkhod-kstressu-i-stressoustoichivosti 
Brunier, A., \& Harris, M. (2020). Substantial investment needed to avert mental health crisis. World Health Organization. https://who.int/ru/news-room/detail/14-05-2020-substantial-investmentneeded-to-avert-mental-health-crisis

Cancio, E., Larsen, R., Mathur, S., Estes, M., Johns, B., \& Chang, M. (2018). Special education teacher stress: Coping strategies. Education and Treatment of Children, 41(4), 457-481. https://doi.org/10.1353/etc.2018.0025

Cunningham, T. G. (2015). A Phenomenological study of the resiliency of special education teachers [Doctoral dissertation, Drexel University]. https://idea.library.drexel.edu/islandora/object/idea\%3A6418

Dev, S. (2018). Major factors affecting the academic achievements of Indian students residing in India (Kerala) and UAE. Research in Social Sciences and Technology, 3(3), 16-31. https://doi.org/10.46303/ressat.03.03.2

Downing, B. (2017). Special Education Teacher Resilience: A Phenomenological Study of Factors Associated with Retention and Resilience of Highly Resilient Special Educators [PhD dissertation, California State University]. https://escholarship.org/uc/item/1dk2s49s

Elmer, T., Mepham, K., \& Stadtfeld, C. (2020). Students under lockdown: Comparisons of students' social networks and mental health before and during the COVID-19 crisis in Switzerland. PLoS ONE, 15(7), 1-22. https://doi.org/10.1371/journal.pone.0236337

Enikolopov, S. N., Boyko, O. M., Medvedeva, T. I., Vorontsova, O. Y., \& Kazmina, O. Y. (2020). Dynamics of psychological reactions at the initial stage of the COVID pandemic. PsychologicalEducational Studies, 12(2), 108-126. https://doi.org/10.17759/psyedu.2020120207

Fimian, M. J., \& Blanton, L. P. (1986). Variables related to stress and burnout in special education teacher trainees and first-year teachers. Teacher Education and Special Education, 9, 9-21. https://doi.org/10.1177/088840648600900102

Gonzalez, T., de la Rubia, M. A., Hincz, K. P., Comas-Lopez, M., Subirats, L., Fort, S., \& Sacha, G. M. (2020). Influence of COVID-19 confinement in students performance in higher education. PLoS ONE, 15(10). https://doi.org/10.1371/journal.pone.0239490

Gritsenko, V., Skugarevsky, O., Konstantinov, V., Khamenka, N., Marinova, T., Reznik, A., \& Isralowitz, R. (2020). COVID 19 Fear, Stress, Anxiety and Substance Use among Russian and Belarusian University Students. International Journal of Mental Health and Addiction, 1-7. https://doi.org/10.1007/s11469-020-00330-z

Holmes, E. A., O’Connor, R. C., Perry, V. H., Tracey, I., Wessely, S., Arseneault, L., \& Ford, T. (2020). Multidisciplinary research priorities for the COVID-19 pandemic: A call for action for mental health science. Lancet Psychiatry, 7, 547-560. https://doi.org/10.1016/S2215-0366(20)30168-1

Ivanova, N. N., \& Makarova, L. N. (2015). Formation of professional competence and professional culture of students-defectologists in the process of studying at the university. Psychological and pedagogical journal Gaudeamus, 1(25), 50-54. http://journals.tsutmb.ru/go/1810-231X/2015/1/50$54 /$

Kamarianos, I., Adamopoulou, A., Lambropoulos, H., \& Stamelos, G. (2020). Towards and understanding of university students' response in times of pandemic crisis (COVID-19). European Journal of Education Studies, 7(7), 20-40. https://doi.org/10.46827/ejes.v7i7.3149.

Kaparounaki, C. K., Patsali, M. E., Mousa, D. P. V., Papadopoulou, E. V., Papadopoulou, K. K., \& Fountoulakis, K. N. (2020). University students' mental health amidst the COVID-19 quarantine in Greece. Psychiatry Research, 2020, August, Article 11311. https://doi.org/10.1016/j.psychres.2020.113111

Katunin, A. P. (2016). Stress resistance as an integrative factor of the joint activity of employees of service teams [Abstract of thesis for a candidate degree in Psychology]. $24 \mathrm{p}$. https://avtoref.mgou.ru/new/d212.155.15/Katunin/avtoref.pdf

Kebbi, M. (2018). Stress and Coping Strategies Used by Special Education and General Classroom Teachers. International Journal of Special Education, 1(33), 34-61. https://files.eric.ed.gov/fulltext/EJ1184086.pdf

Khattar, A., Jain, P. R., \& Quadri, S. M. K. (2020). Effects of the disastrous pandemic COVID 19 on learning styles, activities and mental health of young Indian students. A machine learning 
approach. In Proceedings of the 4th International Conference on Intelligent Computing and Control Systems (ICICCS) (pp. 1190-1195). Madurai, India. https://doi.org/10.1109/iciccs48265.2020.9120955

Klassen, R. M., \& Chui, M. M. (2011). The occupational commitment and intention to quit of practicing and pre-service teachers: influence of self-efficacy, job stress, and teaching context. Contemporary Educational Psychology, 36, 114-129. https://doi.org/10.1016/j.cedpsych.2011.01.002

Kovaleva, Y. M. (2016). The value of resistance to stress in the process of teaching activities. Young Scientist, 4(108), 693-695. https://moluch.ru/archive/108/26117

Nucifora, F., Langlieb, A. M., Siegal, E., Everly, G. S., \& Kaminsky, M. (2007). Building resistance, resilience, and recovery in the wake of school and workplace violence. Disaster medicine and public health preparedness, 1(S1), S33-S37. https://doi.org/10.1097/DMP.0b013e31814b98ae

O'Brien, K. M., Brunsting, N., Bettini, E., Cumming, M., Ragunathan, M., \& Sutton, R. (2019). Special Educators' Working Conditions in Self-Contained Settings for Students with Emotional or Behavioral Disorders: A Descriptive Analysis. Exceptional children, 86, 40-57. https://doi.org/10.1177\%2F0014402919868946

Ragozinskaya, V. G., Kozyrskaya, I. N., \& Stadnik, O. S. (2020). Stress resistance of the future special education teachers in line with the competency-based approach. 50th International Scientific Conference on Economic and Social Development. Book of Proceedings (pp. 508-517). Varazdin Development and Entrepreneurship Agency. https://pure.spbu.ru/ws/portalfiles/portal/60213712/book_of_proceeding.pdf\#page=503

Rustamova, Z. B. (2015). Stress resistance as an important professional quality of teachers-defectologists. Psychological support in the education system. Book of Proceedings (pp. 193-201). Ural University Publishing House.

Simmons, B. L., \& Nelson, D. L. (2007). Eustress at work: Extending the holistic stress model. Positive organizational behavior: Accentuating the positive at work (pp. 40-53). https://doi.org/10.4135/9781446212752.n4

Vizitova, S. Y. (2012). Psychological features of a teacher's resistance to stress and ways to improve it. [Doctoral Dissertation, Yelets State University]. https://www.dissercat.com/content/psikhologicheskie-osobennosti-stressoustoichivosti-pedagogai-puti-ee-povysheniya

Waltz, M. (2016). The efficacy of a stress management and self-care training on student teachers' stress levels. [Doctoral dissertation, Texas Tech University]. https:/ttuir.tdl.org/bitstream/handle/2346/67058/WALTZ-DISSERTATION-2016.pdf?sequence=1

Zhang, M., Bai, Y., \& Li, Z. (2020). Effect of resilience on the mental health of special education teachers: Moderating effect of teaching barriers. Psychology Research and Behavior Management, 13, 537-544. https://doi.org/10.2147/PRBM.S257842 